\title{
Learning Buckets: Helping Teachers Introduce Flexibility in the Management of Learning Artifacts Across Spaces
}

\author{
Juan A. Muñoz-Cristóbal, Juan I. Asensio-Pérez, Alejandra Martínez-Monés, Luis P. Prieto, \\ Member, IEEE, Iván M. Jorrín-Abellán, and Yannis Dimitriadis
}

\begin{abstract}
Technology offers rich opportunities for learning across different physical and virtual spaces. However, most of current across-spaces proposals are either highly teacher-centered, inflexible in the students' self-management of learning artifacts during the enactment, or allow the teacher little/no control of such students' management of artifacts. Moreover, these proposals tend to be disconnected from the practices and tools that are usual in the classroom. How can we achieve a middle ground between keeping the teacher in control of across-spaces situations and, at the same time, providing students with a degree of flexibility to manage learning artifacts? Aiming to address such challenge we propose the notion of learning bucket, and the Bucket-Server, a system implementing such notion. A learning bucket is a container of learning artifacts which are generated and/or accessed across-spaces by the students during the enactment, according to constraints configured by teachers at design time. The responsive evaluation conducted, based on a feature analysis and a pilot study with experts, suggests that learning buckets can help evolve from teacher- to student-centered approaches, while maintaining the teacher in control of students' actions. The evaluation also indicates that the Bucket-Server surpasses the support provided by alternative proposals to across-spaces learning.
\end{abstract}

Index Terms-Artificial, augmented, and virtual realities, Computer uses in education, Education, Ubiquitous computing, Mobile environments

\section{INTRODUCTION}

TECHNOLOGIES like mobile devices, Virtual Learning 1 Environments (VLEs) [1] and Augmented Reality (AR) [2] are blurring the walls of the traditional classroom and helping shape Ubiquitous Learning Environments (ULEs) [3] by combining seamlessly different physical and virtual learning spaces [4,5]. Although ULEs have shown affordances for learning (e.g., regarding accessibility, immediacy, permanency, interactivity, and situation [6]), they are also complex environments that pose challenges for teachers to develop meaningful learning situations [5]. To help teachers create these across-spaces learning situations (i.e., learning situations that seamlessly integrate activities taking place in the different physical and virtual spaces that make up a ULE), many systems

- J.A. Muñoz-Cristóbal, J.I. Asensio-Pérez, A. Martínez-Monés and Y. Dimitriadis are with the GSIC/EMIC Group, Universidad de Valladolid, Paseo de Belén, 15, 47011, Valladolid (Spain) E-mails: juanmunoz@gsic.uva.es, juaase@tel.uva.es, amartine@infor.uva.es, yannis@tel.uva.es

- L.P. Prieto is with the School of Educational Sciences, Tallinn University, Uus-Sadama 5, 10120 Tallinn (Estonia).Email:lprisan@tlu.ee

- I.M. Jorrin-Abellán is with the Department of Secondary and Middle Grades Education, Bagwell College of Education, Kennesaw State University, 1000 Chastain Road, MD 0122, Kennesaw Hall, Bldg. \#1, Kennesaw, GA 30144-5591 (USA) E-mail: ijorrina@kennesaw.edu

***Please provide a complete mailing address for each author, as this is the address the 10 complimentary reprints of your paper will be sent

Please note that all acknowledgments should be placed at the end of the paper, before the bibliography (note that corresponding authorship is not noted in affiliation box, but in acknowledgment section). have been proposed that include authoring tools to translate the teachers' pedagogical ideas into a format interpretable by computers [7-10]. These proposals usually force students to follow a learning design in which most details (e.g., the tools to be used, such as Google Docs ${ }^{1}$, or the concrete learning artifacts to be used by specific students, such as a concrete Google Docs document) are specified a priori, thus limiting student autonomy during the enactment. This "agency issue" is defined by some authors [4] as a clear challenge for practitioners that try to enact across-spaces learning situations. Although a certain level of guidance, or scaffolding, may be desirable in some pedagogical approaches (such as in collaborative learning by using scripts [11]), too much coercion can prevent natural student interactions that are known to promote learning [12]. Therefore, a certain level of flexibility might be desirable in order to enable teachers and students to introduce modifications in the designed learning situation, without altering its pedagogical intention [13]. On the other hand, too much freedom could eventually end up with a situation in which students perform learning tasks (and even interact among them) in a way that does not reflect the pedagogical intentions and the learning goals of the teacher [13]. Therefore, there is a need for a compromise between flexibility and guidance, which should be defined by the teacher based on her pedagogical intentions. Such flexibility should involve only those elements of a learning situation that do not alter its pedagogical essence [13]. In this paper, we focus 
on the flexibility during the enactment regarding the use of learning artifacts: initial resources created by the teacher, as well as intermediate products and final outcomes of the learning process that can be created by the students and shared across activities and spaces. Due to their role as mediators in the learning activities [14, 15], learning artifacts are important elements in different pedagogical approaches, such as Computer Supported Collaborative Learning and Inquiry Based Learning [16, 17].

Some of the proposals enabling teachers to create across-spaces learning situations implement also mechanisms to provide a certain degree of flexibility during the enactment in the students' use of learning artifacts [5, 18, 19]. However, these proposals usually have a limited support for teachers to regulate the degree of flexibility offered to the students $[11,13]$. In addition, these approaches take usually the form of ad-hoc systems, isolated from other activities and systems used in teachers' current practice (e.g., the official VLE of their institution), which can negatively affect teachers' orchestration load [24]. In the present paper we address the research question of how technology can help introduce flexibility in the management of learning artifacts during the enactment of across-spaces learning situations, guided by the teachers' pedagogical decisions, and in a way that is integrated within the teachers' current practice.

In order to help this issue we propose the notion of learning bucket, and the Bucket-Server, a system that implements the aforementioned notion. A learning bucket is a container of positioned learning artifacts (i.e., learning artifacts tagged with space coordinates) that is configured by teachers with constraints that limit what the students can do within it. Learning buckets are included by teachers at design time in the activities of their learning designs. During the enactment, the students generate and access across-spaces the buckets' artifacts. For example, an artifact like a Web 2.0 tool instance (e.g., a Google Docs document or a Flickr ${ }^{2}$ picture) could be generated by students and tagged with geographical coordinates from within a web-based VLE, and be accessed afterwards by other students using AR at the physical location corresponding to the coordinates. The Bucket-Server - the system implementing the notion of learning buckets - enables the integration of learning buckets into different existing software applications created to be used in specific learning spaces (e.g., VLEs in web spaces, AR apps in physical spaces). We evaluated the Bucket-Server by means of a feature analysis (a systematic comparison of the proposal with alternatives in literature) and a pilot study in which experts in across-spaces learning used a Bucket-Server prototype and gave feedback.

The structure of the rest of the document is as follows. The next section presents related work and design requirements proposed for overcoming identified limitations of existing approaches. Section 3 describes the notion of learning bucket and the Bucket-Server system. The evaluation conducted is explained in Section 4, and finally, Section 5 summarizes the main conclusions obtained, as well as the main paths for future work.

\section{Related Work And Limitations}

\subsection{Approaches Providing a Flexible Management of Learning Artifacts During the Enactment}

Many approaches in the literature have proposed solutions that enable the students a flexible management of learning artifacts during the enactment of learning situations. Most of them have focused on web spaces, although there are a number of approaches supporting different physical and virtual spaces.

Among those proposals focused on web spaces and enabling the students a flexible management of learning artifacts during the enactment, there are approaches: i) based on learning design languages, that adapt the activities at runtime according to decisions taken at design time [16, 25-29]; ii) enabling students to "upload" to a VLE artifacts created with general purpose tools (such as Microsoft Office) or ad-hoc authoring tools [30-36]; iii) enabling students to select their learning tools, and sometimes also to define the sequence of activities (these are also known as Personal Learning Environments, PLEs) [37-44]; iv) enabling students to make explicit the learning design they want to conduct [45].

Among those proposals supporting across-spaces and enabling the students a flexible management of learning artifacts during the enactment, we find mainly: i) approaches (mostly for inquiry-based learning) supporting the data collection during field trips and later access to artifacts gathered using a web VLE [6, 17, 20, 21, 46-52]; ii) authoring tools enabling students to create virtual artifacts, and access them from a physical space using AR [22, 23, 53]; iii) mobile location-based educational games enabling students the collection of virtual objects, clues, etc. [54]; iv) authoring tools enabling students to create mobile location-based educational games [55].

\subsection{Limitations of the Reviewed Approaches and Design Requirements}

All the approaches reviewed in Section 2.1 enable the students some flexibility in the management of learning artifacts during the enactment of learning situations. However, many of the described approaches provide limited support for their use in across-spaces learning situations, preventing seamless transitions between activities conducted in different virtual and physical learning spaces [5]. Seamless learning can be facilitated by means of context awareness and adaptivity - i.e. by systems that are aware of the learner's situation, and that adapt the learning contents to such situation $[3,5]$. Nevertheless, many of the reviewed approaches do not enable teachers and students to position learning artifacts in different kinds of spaces, e.g., web and physical spaces (limitation 1). Also, different kinds of learning spaces and activities may entail different technological constraints for such context awareness and adaptivity [56]. Due to these constraints, in across-spaces learning situations the capability of supporting different technological options for contextawareness in different spaces can be relevant in many 
cases. Despite this fact, many approaches do not support different positioning types, such as geoposition, markers, etc. (limitation 2) or do not enable teachers and students to access contextually the same learning artifact from different kinds of spaces, e.g., web and physical spaces (limitation 3).

In addition to the problems for supporting acrossspaces learning situations, several approaches do not allow the integrated use of technologies already existing in teachers' daily practice. This can create seams in the operation of the different systems [57] and can impact negatively in the teachers' orchestration load [24]. This general problem of integration with teacher practice can be reified in two specific limitations that affect most of the reviewed approaches: they do not enable learning situations supported by different ICT-enabled learning environments commonly used in existing educational practice, e.g., multiple VLEs (limitation 4); and they do not enable the integrated use of multiple ICT artifacts and tools commonly used in existing educational practice, as is the case of those of the Web 2.0 (limitation 5).

A final limitation has to do with the capability for teachers to control the degree of flexibility offered to students. An important aspect when giving flexibility to the students is enabling teachers to specify the type of flexibility they want to promote according to their pedagogical intentions without affecting the pedagogical essence of the learning design $[11,13]$. This can be achieved by allowing teachers to configure "extrinsic constraints" (those not affecting the essence), such as those that refer to technological choices (e.g., tools to use), contextual factors (e.g., location) or arbitrary decisions (e.g., number of students per group) [13]. However, many of the approaches reviewed in Section 2.1 do not enable teachers to define multiple kinds of constraints (regarding technological choices, contextual factors, arbitrary decisions, etc.) in order to regulate what students are able to do with learning artifacts (limitation 6).

From the six limitations identified in the previous paragraphs we can derive a list of Design Requirements (DR, see Table 1) that can provide an answer to the challenge of supporting across-spaces learning situations that make an integrated use of technologies already existing in teacher practice, and include teacher-controlled flexibility in the students' management of learning artifacts during the enactment. We conducted an initial screening of the support provided by the approaches reviewed in Section 2.1 to these design requirements (see Table A.1 in the Appendix), and we concluded that all the approaches lack support to many design requirements. Although this lack of support can be reasonable because the reviewed approaches might not have been created considering the challenge that we address in this paper, the screening highlights that the mentioned challenge exists. The following section describes the learning bucket notion and the system implementing it, which following the aforementioned design requirements, aims to address this challenge.
TABLE 1

Design ReQUiREMENTS PROPOSED TO SUPPORT ACROSS-

SPACES LEARNING SITUATIONS THAT INCLUDE TEACHER-

CONTROLLED FLEXIBILITY N THE STUDENTS' MANAGEMENT OF LEARNING ARTIFACTS DURING THE ENACTMENT

DR1. Enable teachers and students to position learning artifacts in different kinds of spaces (e.g., web and physical spaces)

DR2. Support different positioning types (geoposition, markers, etc.)

DR3. Enable teachers and students to access contextually the same learning artifact from different kinds of spaces (e.g., web and physical spaces)

DR4. Enable learning situations supported by different ICT-enabled learning environments commonly used in existing educational practice (e.g., multiple VLEs)

DR5. Enable the integrated use of multiple ICT artifacts and tools commonly used in existing educational practice, as is the case of those of the Web 2.0

DR6. Enable teachers to define multiple kinds of constraints (regarding technological choices, contextual factors, arbitrary decisions, etc.) in order to regulate what students are able to do with learning artifacts

\section{LEARNING BUCKETS}

This section describes the proposed learning bucket notion and the Bucket-Server, a system implementing such notion.

\subsection{What Is a Learning Bucket?}

A learning bucket is a configurable container of learning artifacts that are positioned (i.e. tagged with space coordinates) in different physical and virtual spaces (compliant with DR1, see Table 1). A learning bucket is defined at design time. A teacher can include learning buckets (initially empty or with artifacts) in her design, assigning them, for instance, to different groups in different activities. At design time, the teacher can also configure the bucket with constraints, limiting what students can do within the bucket, for example, what types of artifacts can be included, how the artifacts can be positioned, the number of artifacts that might be generated, etc. The constraints, which can also be modified afterwards by the teacher, limit the flexibility offered to students, in order to promote the coherence of the students' actions with the pedagogical intention decided by the teacher at design time (DR6).

A learning bucket is an element that can be embedded in different third party applications. More specifically, it can be integrated into multiple types of applications for their educational use in different spaces (DR4): typical web-based VLEs (e.g., Moodle ${ }^{3}$, Blackboard ${ }^{4}$ ), mobile AR clients (e.g., Layar ${ }^{5}$, Argon $^{6}$ ), etc. The teacher could decide at design time that a learning bucket will be reused in the same or different environment and space and by the same or different actors. In addition, a learning bucket supports the management - creation, deletion, position-

${ }^{3}$ https:/ / moodle.org. Last access December 2016

${ }^{4}$ http:/ / blackboard.com. Last access December 2016

${ }^{5}$ https:// www.layar.com. Last access December 2016

6 http://argonjs.io. Last access December 2016 


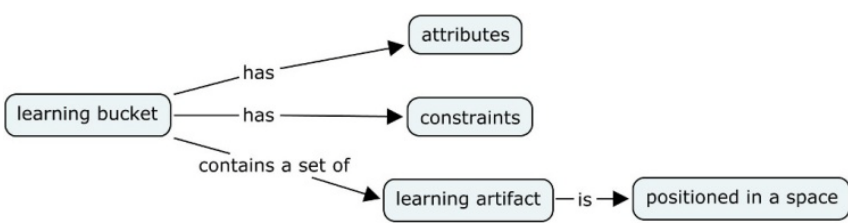

Fig. 1. Learning bucket conceptual model.

ing, etc. - of the multiple types of artifacts that can be included in a bucket - e.g., an implementation of the learning bucket notion could integrate artifacts of multiple widespread Web 2.0 tools (DR5). During the enactment of learning situations, teacher or students can add new learning artifacts, and position them in physical and virtual spaces (DR1).

Learning buckets allow students to take decisions with respect to the artifacts to use, always under the constraints imposed by the teacher. For instance, they could add new artifacts, within predefined limits, they could position such artifacts with different methods, e.g., with geographical coordinates, with fiducial markers, etc. (DR2), and in different physical and virtual spaces - e.g., in a physical space using AR, in a web VLE, or they could select the type of artifact to use. The learning bucket itself could also be positioned in a space. As an example of the applicability of the learning buckets, a group of students could access a bucket in a specific physical space (e.g., a park) using an AR app, and they could create, using the bucket, different artifacts (e.g., documents and pictures), which could be automatically positioned where they are created, or manually positioned in another location and/or another space (e.g., a web-based VLE) (DR3) to be accessed subsequently.

Fig. 1 shows the conceptual model of a learning bucket. A bucket is characterized by a number of attributes (general properties of the bucket) and constraints (properties of the bucket that define what is possible to do in it). A bucket may contain a set of learning artifacts, which are positioned in virtual or physical spaces. A learning artifact can be any virtual resource: a document, a web page, a 3D model, a tool instance, or even another learning bucket.

\subsection{Bucket-Server: A Learning Buckets Implementation}

The Bucket-Server is a system implementing the proposed concept of learning buckets. It allows the management (create, modify, remove, retrieve) of both learning buckets and learning artifacts contained in the buckets, from within other software applications (e.g., VLEs, mobile AR clients, etc.). As aforementioned, such artifacts can be, for example, instances of Web 2.0 tools (e.g., Google Docs, Picasa $^{7}$ or Flickr), web resources (web pages, online documents), or other artifacts accessible through an URI (e.g., a 3D model in an online repository).

\subsubsection{Bucket-Server Architecture and Data Model}

Fig. 2 shows the architecture of the Bucket-Server. The manager is the controller of the system, responsible for

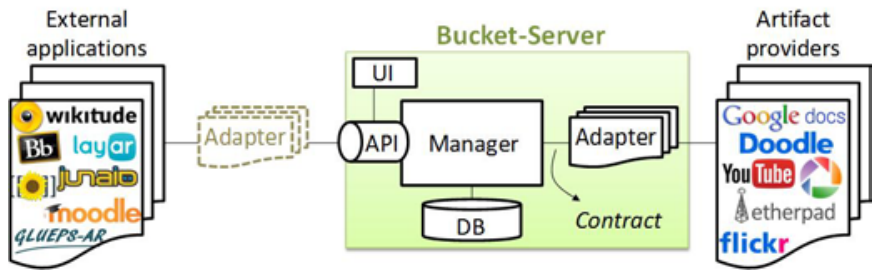

Fig. 3. Bucket-Server architecture.

managing learning buckets and their artifacts, and storing the information (buckets and logs) in the persistent data base (DB). It is the central element, with interfaces with external applications and artifact providers. The manager provides an API for the communication (directly or through adapters) with external applications (e.g., VLEs such as Moodle, mobile AR clients such as Layar, Wikitude 8 , Argon, etc.) (DR4). The manager communicates also with artifact providers through another layer of adapters. These adapters standardize the operations of the manager over the different artifact providers, so that the manager can always use the same set of operations defined in a contract ${ }^{9}$, independently of the API of each artifact provider. An artifact provider could be, for instance, a commonly used Web 2.0 tool (e.g., Google Docs) (DR5). The Bucket-Server has also a user interface (UI), which acts as a client of the manager, using the API to interact with it. The UI allows the graphical operation of buckets and their artifacts independently of the learning environment in which they are embedded.

Fig. 3 shows the data model implemented in the Bucket-Server. In order to enable the positioning and access of artifacts and buckets in different physical and virtual spaces (DR1, DR3), we have used the Point of Interest (POI) model [7]. Such POI model is comprised of the more common attributes present in different systems, data models and specifications ${ }^{10}$ describing resources positioned in physical spaces. In the Bucket-Server data model, both learning artifacts and learning buckets are POIs, inheriting the POI's attributes (e.g., the attribute positionType which allows different positioning modes, such as geographical coordinates, QR codes, or fiducial

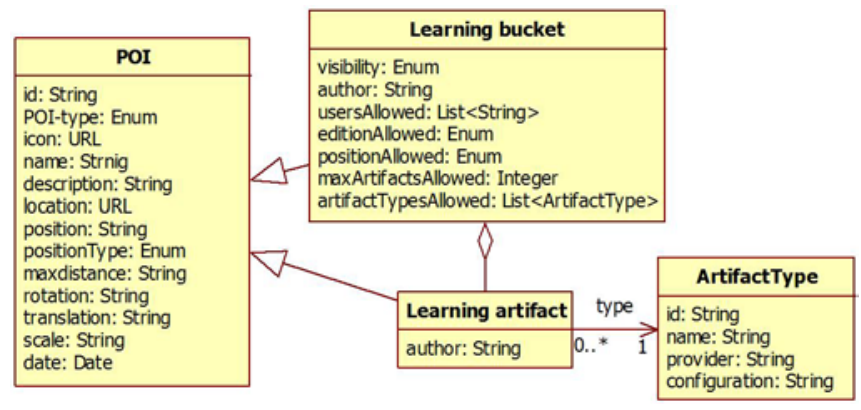

Fig. 2. Bucket-Server data model.

${ }^{8}$ http:/ / www.wikitude.com. Last access December 2016.

9 Therefore, the contract is the set of expected behaviors and APIs that the adapters needs to implement to communicate with the Bucket-Server manager $[58,59]$

10 It is interesting that a new IEEE Working Group is working in a model for AR Learning Experiences and in current drafts of the model they are also considering a notion of "Point of Interest" (see https://standards.ieee.org/develop/wg/AR-LEM.html

https://arlem.cct.brookes.ac.uk/ last access December 2016 


$\begin{array}{|ccc|}\text { Definition of activities } & \begin{array}{c}\text { Activity 1 (classroom) } \\ \text { Using Moodle (web space) }\end{array} & \begin{array}{c}\text { Activity 2 (park) } \\ \text { Using Junaio (physical space) }\end{array} \\ \begin{array}{c}\text { Creation of learning bucket and } \\ \text { configuration of constraints }\end{array} & \begin{array}{c}\text { Creation and positioning of } \\ \text { learning artifacts }\end{array} & \begin{array}{c}\text { Access to positioned } \\ \text { learning artifacts }\end{array}\end{array}$
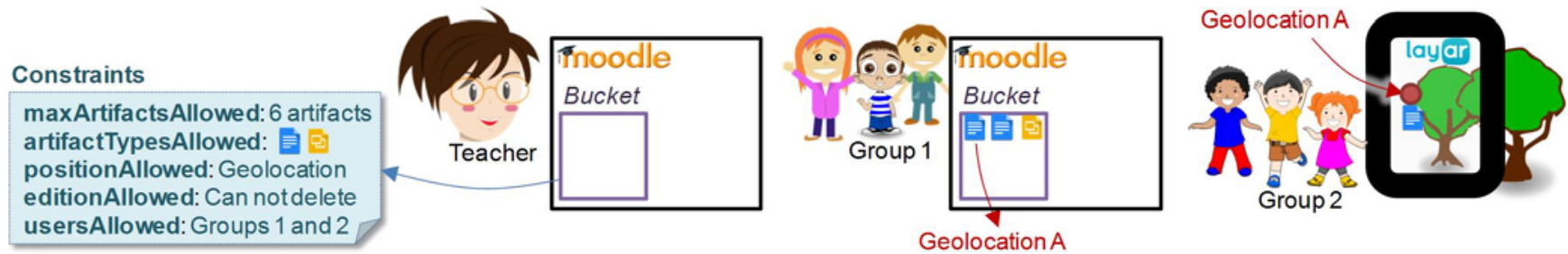

Fig. 4. Example of the use of a learning bucket.

markers, DR2). Additionally, as shown by Fig. 3, the learning bucket can contain learning artifacts. A learning artifact can be of different types, corresponding to the artifact providers integrated in the Bucket-Server (see Fig. 2). The information element ArtifactType identifies the type of artifact, its provider, and the configuration fields (which will be displayed in the UI) necessary to configure its artifacts. Besides the attributes inherited from the POI model, a learning bucket defines its own ones: visibility to enable the teacher to hide the bucket and its artifacts (e.g., in the sequence of activities of a VLE like Moodle); author (the user that created the bucket); and a set of attributes that define the constraints, restricting what is possible to be done in the bucket.

The data model is extensible and new attributes can be included in the data model. However, in order to facilitate the configuration of learning buckets by the teachers we have prioritized simplicity over completeness. Thus, the current implementation of the data model supports a set of constraints which can be complemented in the future with new ones, in case they are needed. The constraints that are included are listed below, classified according to the conceptualization of extrinsic constraints stated by Dillenbourg \& Tchounikine [13] (see Section 2) (DR6):

- Regarding technological choices: artifactTypesAllowed - restrictions over the possible types of artifacts that can be used, among the set supported by the Bucket-Server installation.

- Regarding contextual factors: positionAllowed - restrictions over the positionType POI attribute.

- Regarding arbitrary decisions: i) usersAllowed - restrictions over the students allowed to access the bucket; ii) editionAllowed - possible operations that the students can conduct with artifacts, e.g., create, remove, etc.; iii) maxArtifactsAllowed - maximum number of artifacts that can be created in a bucket.

A learning bucket can be reused by the same or different applications, across multiple physical and virtual spaces, to achieve continuity in the different activities of a learning situation. Fig. 4 shows an example of the use of a learning bucket in a learning situation about botany. In the figure, the teacher defines at design time two activities in which a learning bucket will be used, the first one to be conducted in the classroom using Moodle, and the second one in a park using an AR app such as Layar [60]. She also creates a learning bucket from within a VLE such as Moodle (web space), and configures the bucket with constraints to limit what students will be able to do. The teacher allows the students of Groups 1 and 2 to create up to 6 artifacts in the bucket, of the types Google Docs and Google Slides. She also enables the students to geolocate the artifacts they create, and she does not allow students to delete artifacts. During the enactment, Group 1, using Moodle (Activity 1, web space) creates Google Docs and Google Slides with information related to a type of tree present in a nearby park. They also position such artifacts in the location of the trees using geographical coordinates. In Activity 2, Group 2, using Layar in the park (physical space), accesses at the location of the aforementioned trees the artifacts created by Group 1 in the previous activity.

\subsubsection{Bucket-Server Prototype}

We have developed a prototype of the Bucket-Server aiming to explore the learning bucket notion and its use in across-spaces learning situations. The technologies used in the prototype are Java for the manager and the adapters, HTML and Javascript for the user interface, and MySQL for the buckets database. We have created an artifact provider adapter for the GLUE! [61] Tool Mediator ${ }^{11}$, enabling with a single adapter to include in the buckets all the artifact types supported by GLUE! (multiple Web 2.0 tools, widgets, etc.). Also, we have created an application adapter for the GLUEPS-AR system [7]. GLUEPS-AR is an across-spaces orchestration system that enables the deployment ${ }^{12}$ of learning designs - which could have been defined in a variety of authoring tools in ULEs composed of web VLEs and/or mobile AR clients. With the Bucket-Server prototype, learning buckets are used as any other learning artifact in GLUEPS-AR, and they can be included at any point of the design, being reused in different activities, etc. Since GLUEPS-AR sup-

\footnotetext{
11 A Tool Mediator is an intermediary system that enables the integration of multiple tools with a single adapter [62]. We used GLUE! in the prototype in order to benefit from the existing GLUE! adapters, but any other Tool Mediator could be used.

12 I.e., the setting up of the technological implementation in which the enactment will be carried out
} 
TABLE 2

DatA GATHering TeChniques and LABELS USED to Quote Them Along THE TeXT

\begin{tabular}{ll}
\hline Technique & Type of data \\
\hline $\begin{array}{l}\text { Collection of } \\
\text { participants' } \\
\text { generated } \\
\text { artifacts }\end{array}$ & $\begin{array}{l}\text { Collection of a diverse set of artifacts generated by the trainers (learning design, wiki pages/course, learn- } \\
\text { ing buckets, learning artifacts, pictures, emails) and the experts (learning artifacts, emails). Used to regis- } \\
\text { ter the use of learning buckets, and to complement the observation with information of the learning arti- } \\
\text { Observation } \\
\text { facts generated. }\end{array}$ \\
$\begin{array}{l}\text { Audio/video recordings and observation notes taken during the workshop with the experts, to register } \\
\text { their actions, impressions, and other emergent issues. }\end{array}$ \\
[Obs] \\
$\begin{array}{l}\text { Feedback questionnaires composed of open-ended and closed items regarding the use of buckets; and } \\
\text { score sheets of the support provided by systems to a set of features. Used to collect the opinions of the } \\
\text { experts and the evaluation team about the Bucket-Server. }\end{array}$ \\
[Score]
\end{tabular}

ports across-spaces learning situations, once the buckets are created, they can be deployed into the learning environments supported by GLUEPS-AR (VLEs and mobile AR clients). For example, in the case of a VLE such as Moodle, the bucket would be embedded in the corresponding course deployed by GLUEPS-AR. As GLUEPSAR integrates multiple VLEs (Moodle, Mediawiki) and multiple mobile AR clients (Junaio ${ }^{13}$, Layar, Mixare ${ }^{14}, \mathrm{QR}$ code readers) [60], learning buckets can be included in learning designs making use of any combination of all these applications. Thus, buckets and their artifacts can be positioned in different spaces (web and physical), and can be accessed (buckets and artifacts) from different spaces and positioning types (e.g., fiducial markers, QR codes, geoposition).

\section{Evaluation}

We have carried out an evaluation to explore the research question that guides our work:

How can technology help introduce flexibility in the management of learning artifacts during the enactment of acrossspaces learning situations, guided by the teachers' pedagogical decisions, and in a way that is integrated within the teachers' current practice?

We formed an evaluation team composed of five researchers with different background, technological or pedagogical. The evaluation consisted of (1) a pilot study with experts, where the evaluation team performed an across-spaces learning situation in a workshop with a group of experts in the across-spaces learning field; and (2) a feature analysis in which the evaluation team scored the support provided to the design requirements posed in Section 2, both by the Bucket-Server and by alternative approaches in the literature.

\subsection{Method}

For the evaluation, we have followed the Evaluandoriented Responsive Evaluation Model (EREM) [63]. The EREM is a framework based on a Responsive Evaluation approach [64], and it is conceived to guide evaluators of innovations in a wide range of ubiquitous and collaborative learning situations. This kind of evaluation is framed within an interpretive research paradigm $[65,66]$, aiming to a deep understanding of the particularity and the richness of the concrete phenomena under study, instead of

13 https://en.wikipedia.org/wiki/Junaio. Last access December 2016 pursuing statistically significant results or generalizations. Due to this fact, it is usual in interpretive research to use small and purposive samples of people, and study them in depth [67].

To explore the research question we have carried out an anticipatory data reduction process [67] during the evaluation design (see Fig. 5). We defined an evaluative issue as the main conceptual organizer of the evaluation: Do learning buckets help teachers introduce a controlled but flexible management of learning artifacts during the enactment of across-spaces learning situations that may involve technologies existing in current practice? If so, how? We divided such issue into two manageable topics to help us better illuminate the complexity of the proposed issue, and we used the Bucket-Server prototype to investigate the topics. The first topic focused on exploring if the Bucket-Server provides flexibility in the management of learning artifacts during the enactment of across-spaces learning situations. Such topic was aimed to understand the general support of the Bucket-Server to the flexible management of learning artifacts during the enactment. The second topic centered on exploring the support provided by the Bucket-Server to the design requirements defined in Section 2, and therefore, on how its features overcome the limitations of current approaches that provide flexibility during enactment of learning situations. We also divided the second topic in three subtopics (see Fig. 5), again to help us reduce the complexity of the topic. All these topics were studied through a set of informative questions. The schema "research question - issue - topics - (subtopics) - informative questions" (see Fig. 5) also guided the data collection during the evaluation, which was carried out using multiple data sources, thus ensuring the trustworthiness of the evaluation. Table 2 describes the different data gathering techniques employed, and their purpose in the evaluation process.

Fig. 6 illustrates the evaluation process followed, divided into happenings (evaluation events). The process involved a pilot study [68] with experts, as well as a feature analysis (i.e., a systematic comparison of the features of different approaches or systems). The involvement of experts in this pilot study allows us to confirm if the problem tackled by the learning buckets is considered as significant in the field, and that the solution provided by the learning buckets is original. The feature analysis also helps us confirm the originality of the learning buckets. Through the pilot study we explored both topics (flexibility during the enactment and features), and the feature analinformation. 


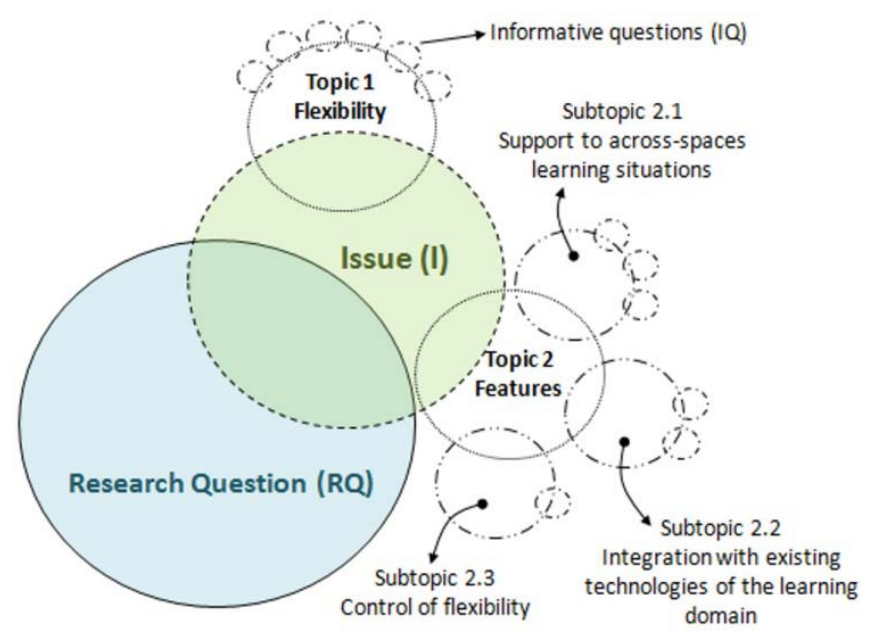

Fig. 5. Anticipatory data reduction showing research question (RQ), issue (I), topics, subtopics and informative questions (IQ)

ysis focused on topic 2 (features). During the pilot study, different data gathering techniques and sources were used: naturalistic observations, web-based questionnaires, and collection of artifacts generated by the participants. Data analysis was carried out using NVivo ${ }^{15}$ software, and with the anticipatory data reduction schema (see Fig. 5) acting as an initial category tree [67]. With the feature analysis we explored whether the support of learning buckets to the defined design requirements improves the support provided by other approaches in the literature. We followed the feature analysis screening method of the DESMET evaluation methodology [69]. The screening method is a qualitative feature-based evaluation that can be performed by an evaluation team (in our case five researchers), who determines the features to be assessed, the rating scale, and does the assessment. Questionnaires (score sheets, see Fig. 6) are used to assess the features, and the scores are summarized in a final report called evaluation profile.

During the evaluation, triangulation of methods, techniques and sources were used, to cross-check data as well as to ensure the quality, credibility and rigor of the responsive evaluation and its results [70]. The different data gathering techniques used in each happening are shown in Fig. 6 with the labels used all along the text to refer to them.

\subsection{Pilot Study with Experts}

\subsubsection{Context}

The pilot study took place around a workshop (Madrid, May 2013) of a Spanish R\&D project called Educational Reflected Spaces ${ }^{16}$, related to learning across physical and virtual spaces. Thirty researchers from three Spanish universities (University of Valladolid, Pompeu Fabra University of Barcelona and Carlos III University of Madrid) attended the workshop.

\subsubsection{Intervention}

$15 \mathrm{http}$ ///www.qsrinternational.com/products.aspx. Last access December 2016

16 http:/ /eee.gast.it.uc3m.es. Last access December 2016
In order to explain and demonstrate the notion of learning buckets and the Bucket-Server system, two members of the evaluation team created, deployed (using GLUEPSAR integrated with the Bucket-Server prototype) and enacted an across-spaces learning situation consisting of activities before, during and after the workshop. The learning situation was aimed at the collaborative creation of a "virtual Madrid" inside the classroom, using learning buckets, in order to help understand the notion of learning buckets and the Bucket-Server system, as well as their affordances. Fig. 7 describes the learning situation conducted. The pedagogical objective of the learning situation was that the researchers attending the workshop could learn about some representative monuments and buildings of Madrid, the city wherein the workshop was developed. Eight of the researchers attending the workshop completed at least three of the four activities of the learning situation, while the rest of the participating researchers only completed the activities conducted during the workshop. We will refer throughout the paper to these eight researchers as the "experts" (who assessed the learning buckets), in order to distinguish them from the rest of the workshop attendants. The experts split into three groups (one per university), and in a first activity, remotely and previously to the workshop, they used learning buckets embedded in a wiki-based VLE to create learning artifacts (using Web 2.0 tools, images and web contents) with information about some monuments and historical buildings of Madrid. They also associated the artifacts with AR markers. Such artifacts were accessed in a subsequent face-to-face activity by the experts during the workshop, using the Junaio mobile AR client. AR enabled the small-scaled virtual recreation of a nearby outdoor space in the classroom, facilitating the group discussion and collaborative work about such space [71]. Finally, there were a face-to-face lecture about learning buckets, and a remote activity after the workshop in the wiki-based VLE, in which the experts watched a video explaining how the used learning buckets had been created.

\subsubsection{Happenings}

During the first happening (H1 in Fig. 6), the trainers (two members of the evaluation team) designed and deployed the learning situation described in Fig. 7 using the WebCollage authoring tool [72] and GLUEPS-AR integrated with the Bucket-Server. They created learning buckets using the GLUEPS-AR user interface, which were embedded in the wiki-based VLE to be used during the study. Then, five experts conducted the remote activity prior to the workshop using the wiki-based VLE (H2). In the remote activity, the five experts used learning buckets to create and position learning artifacts. The trainers monitored the artifacts created by the five experts in the wiki, during the workshop (H3), all eight experts (together with the rest of the researchers attending the workshop) conducted the aforementioned face-to-face activities of the learning situation (a virtual Madrid and a lecture) (see Fig. 7). In a new happening (H4), seven experts finished scaffolding them when needed. In the next happening 


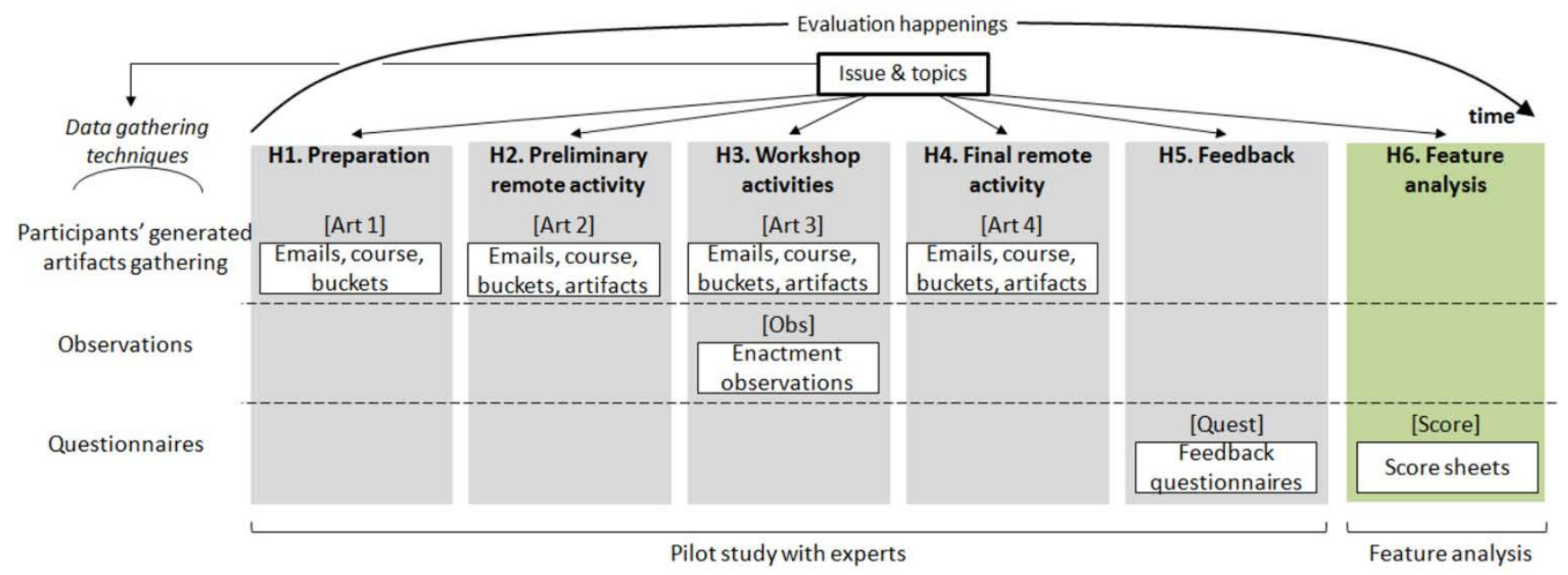

Fig. 6. Evaluation happenings $(\mathrm{H})$ and data gathering techniques used during the evaluation

remotely the remaining learning activity. Finally (H5), we gathered feedback about the learning buckets through a web-based questionnaire. Seven experts from the three universities answered the questionnaire, including experts in AR, blended learning, across-spaces learning and orchestration of learning situations (see Table A.2 in Appendix).

\subsubsection{Findings}

This section describes the main findings obtained during the pilot study, organized following the anticipatory data reduction diagram (see Fig. 5). Throughout the text, the data sources that support the different assertions are indicated with labels (see Fig. 6) between square brackets. Due to space restrictions, only a selection of excerpts of the data sources is included in the text. It is important to emphasize that, in accordance with the responsive evaluation approach followed, we do not aim at obtaining statistically significant results or generalizations, but to explore in depth, and understand, the experts' perspective and impressions regarding the learning buckets.

\subsubsection{Topic 1 (Flexibility During the Enact-}

\section{$\underline{\text { ment) }}$}

This topic focuses on exploring the support provided by the Bucket-Server to the flexible management of learning artifacts during the enactment of the across-spaces learning situation conducted. Table 3 shows the type, positioning type and number of the buckets and buckets' artifacts created by the trainers and the participants during the different activities [Art 1-3]. The results of the evaluation were positive regarding the flexibility provided by the Bucket-Server in the management of learning artifacts during the enactment of across-spaces learning situations [Art 1-3, Quest]. In the exploratory questionnaire, the experts recognized as positive such flexibility provided by the learning buckets (see questions 1, 2 and 3 in Table A.3 in Appendix [Quest]). They also acknowledged that the Bucket-Server can enable teachers to share their management load with the students. In the questionnaire, the participants agreed with the assertion regarding the management load (see question 4 in Table A.3 [Quest]), and some other comments of the experts in relation to the benefits of the learning buckets confirm such view (" IIt is interesting that] the students themselves participate in the instantiation [i.e., the implementation] of a learning situation", "[bucket benefits include] the implication of the students in the activity, a meta-cognitive learning [...] and lightening the work of the teacher" [Quest]). The experts acknowledged also that the Bucket-Server can aid in the adaptation when facing emerging events during the enactment of acrossspaces learning situations (see question 5 in Table A.3 [Quest]).

In addition, the experts' feedback was very positive in the questionnaire regarding how the Bucket-Server would be able to facilitate students' own decisions about learning artifacts, being responsible for their learning process in across-spaces learning situations (see questions 6 and 7 in Table A.3; it was also supported by several of the open-ended answers, such as "[A benefit of learning buckets is that] they allow to pass from teacher-centered approaches to student centered ones" [Quest]). Such capabilities of the Bucket-Server to promote decision making and responsibility were also observed during the enactment of the learning situation, in which the experts decided the artifacts they wanted to create, choosing between different artifact types (Google Docs documents, web content and images) [Art1-2].

An interesting finding was that although the experts

TABLE 3

BuCKETS AND BuCKETS' ARTIFACTS CREATED by TRAINERS AND PARTICIPANTS [ART1-3]

\begin{tabular}{|c|c|c|c|c|c|}
\hline \multicolumn{3}{|l|}{ Trainers } & \multicolumn{3}{|l|}{ Participants } \\
\hline Artifact type & Positioning type & No. artifacts & Artifact type & Positioning type & No. artifacts \\
\hline Bucket & Web & 3 & Google Docs & Fiducial marker & 2 \\
\hline Bucket & QR code & 1 & AR image & Fiducial marker & 6 \\
\hline Picasa picture & Web & 1 & Web content & Fiducial marker & 3 \\
\hline
\end{tabular}




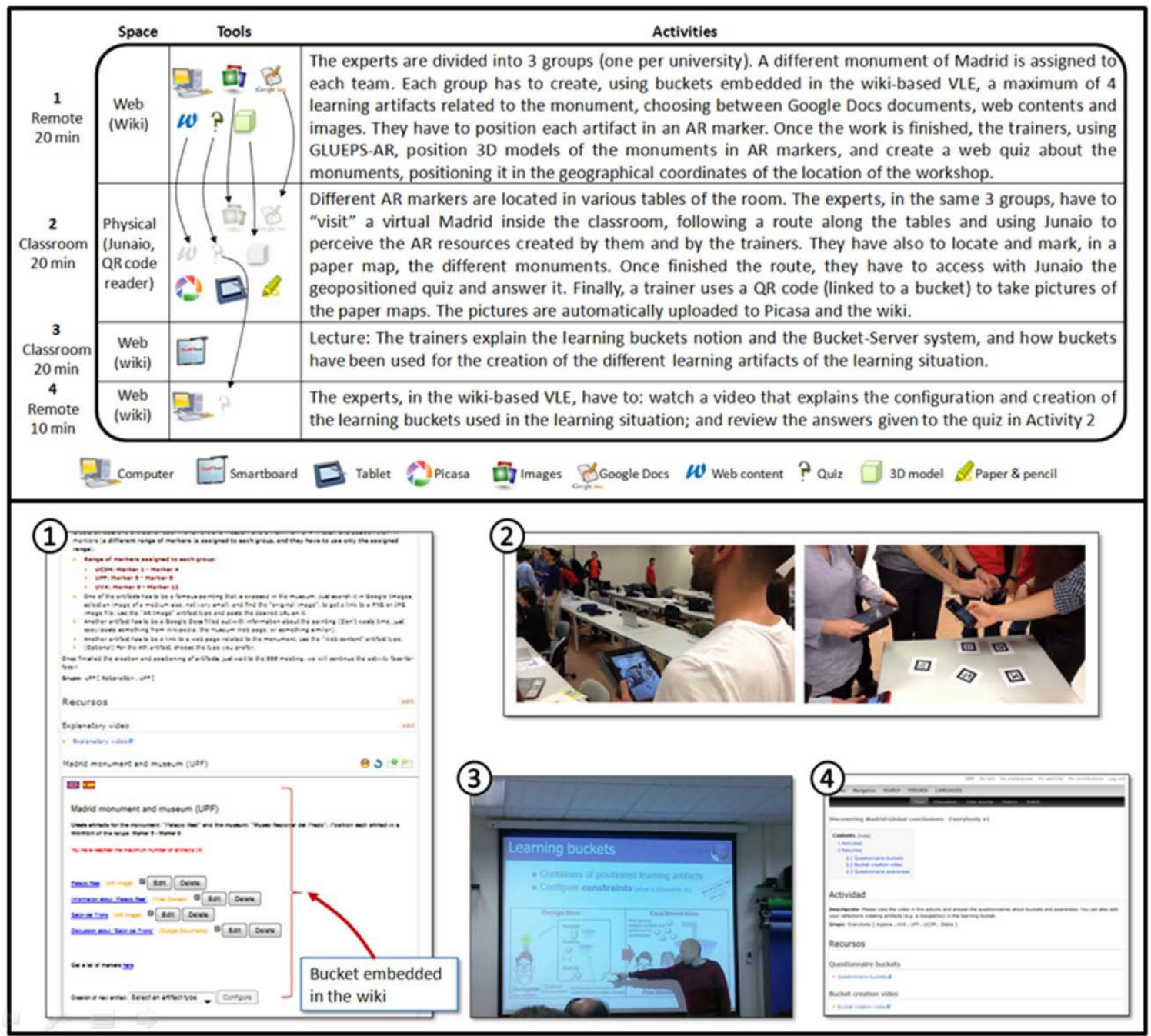

Fig. 7. Virtual Madrid in the classroom using learning buckets. Description of the learning situation (top) and snapshots of the four activities (bottom)

considered the Bucket-Server easy to use by both teachers and students (see questions 8 and 9 in Table A.3 [Quest]), the experts' response regarding the ease of use by teachers was the lowest rated item in the questionnaire (question 9 in Table A.3 [Quest]). One of the experts recommended the improvement of the Bucket-Server user interface: "The interface to manipulate buckets is not very intuitive. For instance, to create an artifact, you have to go to the bottom, and the creation-button is not identified with any typical icon for creating something new" [Quest].

The Bucket-Server was also considered useful by the experts. They considered the teacher-configurable constraints useful to restrict what students can be able to do (see question 10 in Table A.3 [Quest]). Experts agreed also with assertions regarding that buckets' constraints allow teachers to keep control of what students can do with buckets (see question 11 in Table A.3 [Quest]), and about the importance of such constraints to the subsequent management of student-created artifacts by the teacher (see question 12 in Table A.3 [Quest]). Some experts suggested the inclusion of additional constraints, such as temporal restrictions or related to social organization ("aspects of social organization in the access to the bucket: hierarchical, democratic, etc" [Quest]). Some of the benefits of learning buckets highlighted by the experts (in addition to those already mentioned) were: the support for students to participate in the creation of learning artifacts with information for different spaces (which participants recognized that could be also applicable to learning environments such as PLEs and Massive Open Online Courses, MOOCs); being a generic container allowing the grouping of artifacts in both design and enactment time; or the fact that they enable collaboration of participants in-situ and participants in virtual environments; and the runtime awareness of what is happening during the enactment [Quest].

\subsubsection{Topic 2 (Features)}


All the features corresponding to the design requirements posed in Section 2 were supported during the learning situation. Thus, the Bucket-Server enabled trainers and experts to position learning artifacts in different spaces using different positioning types (see, e.g., Table 3 [Art13], and question 13 in Table A.3 [Quest]). The trainers positioned a bucket in a $\mathrm{QR}$ code to upload pictures to Picasa, and such pictures were positioned only in the wiki. The experts positioned the learning artifacts they created in fiducial markers. An email from the trainer to one of the groups illustrates the positioning affordance: " $I$ see that you have created a couple of artifacts in the wiki [...], but they are not positioned correctly: One is positioned in a $Q R$ code and the other one is not positioned [in the physical space]. You should position them using markers (option 'Position in a marker') from the range you are assigned (Marker 5 to Marker 8)" [Art 2]. Also, an expert stated in the questionnaire that "I see clearly how to position resources in the physical world, but I don't see how to position them in the [3D] virtual world. In that case, it would be Virtual Reality instead of AR, but it would be very useful" [Quest]. The learning artifacts created by trainers and experts were accessed subsequently from the wiki as well as from the physical classroom using AR (some observation notes and video annotations illustrate this: "the group of the Pompeu Fabra University starts to see the artifacts", "the group of the Carlos III University is using Junaio and viewing with AR the artifacts: images, Google Docs documents, etc" [Obs]). Finally, evidence gathered showed that the Bucket-Server allowed a continuity of the learning experience in activities performed in different physical and virtual spaces. During the learning situation, the experts created artifacts remotely in a webbased VLE (the wiki), which were afterwards accessed from the physical classroom using AR. In addition, artifacts created from the physical classroom were subsequently accessed from the wiki (pictures from the paperbased maps taken by the trainer) [Art 2-4]. Results in the questionnaire valued very positively that the BucketServer enables such continuity (see question 14 in Table
A.3 [Quest]), and leveraging multiple physical and virtual spaces (see question 15 in Table A.3 [Quest]). Also, one of the experts suggested a modification of the user interface to include positioning types enabling the use of artifacts in 3D virtual world spaces [Quest].

Moreover, the Bucket-Server enabled the trainers and the experts the integrated use of multiple systems already existing in the educational domain [Art 1-4, Obs, Quest]: commonly used artifacts and tools, such as Web 2.0 tools (Google Docs, Picasa), different web contents and images; and different kind of learning environments such as a wiki-based VLE and the Junaio mobile AR client ("the group of the Pompeu Fabra University is accessing with Junaio a Google Docs document [...] created by some of the groups and positioned in a marker" [Obs]).

In addition, the Bucket-Server enabled the trainers to configure constraints for limiting what experts were able to do within buckets [Art 1-4, Quest]. These constraints were the maximum number of artifacts that could be created in the buckets; the permissions to create, update or delete artifacts; the available artifact types that the participants could use; and allowing the experts to position artifacts.

\subsection{Feature Analysis}

A feature analysis was carried out by the evaluation team (composed of 5 researchers) in order to compare systematically the support provided by the Bucket-Server and by current approaches to the design requirements indicated in Table 1 (topic 2, see Fig. 5). It is important to note that the feature analysis does not outline the general characteristics or quality of the approaches. It is specifically focused on the systematic comparison of the indicated features, which were defined to help introduce flexibility in the management of learning artifacts during the enactment of across-spaces learning situations. Since most of the approaches were not designed with this specific purpose, it is reasonable that they do not support the indicated design requirements as the Bucket-Server.

TABLE 4

EVALUATION PRofile OF THE DifFERENT APPROACHES

\begin{tabular}{|c|c|c|c|c|c|c|c|c|c|c|c|c|}
\hline Features & \multicolumn{12}{|c|}{ Conformance score obtained } \\
\hline $\begin{array}{l}\text { DR1. Enable teachers and students to position learning artifacts in different kinds } \\
\text { of spaces (e.g., web and physical spaces) }\end{array}$ & 1 & 0 & 0 & 3 & 4 & 0 & 1 & 4 & 2 & 4 & 0 & 5 \\
\hline $\begin{array}{l}\text { DR3. Enable teachers and students to access contextually the same learning artifact } \\
\text { from different kinds of spaces (e.g., web and physical spaces) }\end{array}$ & 0 & 0 & 0 & 1 & 4 & 0 & 1 & 4 & 1 & 2 & 1 & 5 \\
\hline $\begin{array}{l}\text { DR4. Enable learning situations supported by different ICT-enabled learning envi- } \\
\text { ronments commonly used in existing educational practice (e.g., multiple VLEs) }\end{array}$ & 0 & 5 & 5 & 0 & 0 & 5 & 0 & 0 & 3 & 0 & 0 & 5 \\
\hline $\begin{array}{l}\text { DR5. Enable the integrated use of multiple ICT artifacts and tools commonly used } \\
\text { in existing educational practice, as is the case of those of the Web } 2.0\end{array}$ & 0 & 4 & 4 & 1 & 0 & 4 & 4 & 0 & 4 & 3 & 4 & 4 \\
\hline$\%$ over the total possible & 10 & 36,67 & 40 & 30 & 40 & 36,67 & 33,33 & 40 & 40 & 40 & 30 & 93,33 \\
\hline
\end{tabular}


The feature analysis was carried out in three stages: initial screening, assessment, and discussion panel. In the first stage, a member of the evaluation team screened the support provided by alternative approaches to the design requirements (Table A.1) in order to select the approaches to be compared with the Bucket-Server. We selected the approaches that provide some support, according to the screening carried out, in at least two of the three aspects of the explored challenge, namely: across-spaces support, integration with teaching practice, and teacher control of students' flexibility (see Section 2, Fig. 5 and Table A.1). Based on this criterion, eleven approaches were selected to be assessed by the evaluation team (see Table 4).

During the second stage, each member of the evaluation team scored (in a 0-5 scale), using score sheets [Score] as recommended by DESMET [69], the support of different approaches to the design requirements. Each evaluator rated at least two approaches in addition to the Bucket-Server. In order to score an approach, the evaluators studied the related publications and manuals, and tested the tools if they were accessible.

Finally, the evaluation team, jointly in a 3-hour panel, shared the score sheets, discussed conflicting criteria, and generated an evaluation profile agreeing a final score for each approach. Table 4 shows such evaluation profile.

The Bucket-Server was the system with the highest score, and the only one supporting all the features. The next scored systems were iTEC Composer [35], nQuire [20], the service-based framework for interoperability between VLEs and PLEs [38], Lemonade [48], and the LESTS GO project prototype [21]. Lemonade and nQuire showed to be limited in the integration of existing technologies in the educational practice, and the service-based framework [38] showed a restricted support to acrossspaces learning situations. iTEC Composer presented limitations in the support of across-spaces learning situations and in the regulation of the flexibility offered to the students. The LETS GO project prototype showed some limitations in the integration of existing technologies in the educational practice, and in the teacher regulation of the student flexibility during the enactment. It is interesting to observe that the Bucket-Server's across-spaces support (features DR1 to DR3) stands out from the acrossspaces support provided by the rest of approaches. It is especially prominent in the possible use of different positioning types (DR2), which does not restrict a limited use of a specific kind of space (e.g., to outdoors using GPS). Another aspect that emerged from the analysis was that almost all the systems implement some mechanism for allowing teachers to regulate what the students can do with learning artifacts. However, only six systems (including the Bucket-Server) propose different types of configurable constraints regarding, e.g., technological choices, contextual factors or arbitrary decisions.

\section{CONCLUSION}

The evidence gathered in the evaluation suggests that the Bucket-Server, and therefore the learning bucket notion, can provide teacher-controlled flexibility in the manage- ment of learning artifacts during the enactment of acrossspaces learning situations that are not isolated from the teachers current practice. Thus, the learning buckets can enable teachers to configure different types of constraints regarding technological choices, contextual factors and arbitrary decisions to control the freedom of the students during the enactment. Also, the learning buckets showed a better support to across-spaces learning situations than the support provided by alternative approaches. In addition, the learning buckets enable the integrated acrossspaces use of widespread tools, such as a wiki, Google Docs or Picasa. Moreover, evaluation evidence suggests that learning buckets can enable students to participate in the technological implementation of the learning situations, and can be an interesting instrument to support the evolution from teacher-centered approaches toward more student-centered ones in across-spaces learning.

Such flexibility can be especially important in approaches which are inherently rigid in what students are able to do during the enactment, as is the case of those proposals, such as GLUEPS-AR, based on the use of learning design authoring tools. In such proposals it is usual that tools to use or artifacts to produce during the enactment are completely specified a priori. Learning buckets, as illustrated during the evaluation, can provide teacher-controlled flexibility to enable teachers and students to manage their learning artifacts across-spaces.

As an alternative to the use of authoring tools and a deployment system such as GLUEPS-AR, we plan to explore in the future the direct integration of the BucketServer with learning environments such as widespread VLEs. Such integration could convert a learning environment not natively supporting across-spaces learning situations (e.g., Moodle), into a system where teachers and students create across-spaces contents (e.g., resources to be used in subsequent activities in other spaces different to the web one of Moodle). Also, some of the possible enhancements detected during the evaluation should be explored in the future, such as the possible integration of $3 \mathrm{D}$ virtual worlds and the improvement of the user interface.

Regarding the learning buckets configurable constraints, although the initial set of configurable constraints in the data model of the Bucket-Server is rather simple, it could be extended for enabling more complex regulation of the degree of flexibility. In particular, the current implementation of constraints is limited in its capability for mapping the pedagogical intentions of the teachers. The current constraints demand an effort for teachers to "translate" their pedagogical intention to constraints, and not all pedagogical intentions can be supported. Similarly, the current constraints implement a simple access control based on the W3C Basic ACL ontology ${ }^{17}$, although other more complex access controls could be implemented (e.g., a context-aware role-based access control [73]). We considered that a simple set of constraints was the best way to start exploring the concept, but future research could focus specifically on the possi- 
ble constraints that could be configured and their effect on usability and cognitive demand, as pointed by some of the participants in the evaluation.

This paper presents a first step in our research of learning buckets. In this first step we have obtained evaluation evidence suggesting that the proposal is relevant (by the pilot study with experts) and original (by the feature analysis) to help introduce flexibility in the management of learning artifacts during the enactment of across-spaces learning situations. Nevertheless, in order to explore in depth the help provided by the learning buckets to teachers in their real practice, we plan to continue our research by using the Bucket-Server in other educational situations with teachers and students, including different pedagogical approaches and technologies. We also plan to explore how the Bucket-Server could provide support for reusing learning artifacts in different buckets and in different positions and spaces. This reuse would extend the possible range of across-spaces learning situations that teachers could create with learning buckets. It could also enable the reuse of learning buckets and their artifacts out of the scope of the learning situations in which they are created, e.g., following a similar approach than the learning object repositories [74].

\section{ACKNOWLEDGMENT}

This research has been partially supported by the Spanish Ministry of Economy and Competitiveness (project TIN2014-53199-C3-2-R) and the Regional Government of Castilla y León (project VA277U14). The authors thank the 2013 EEE Project Workshop participants and the rest of the GSIC/EMIC research team for their ideas and support.

\section{REFERENCES}

[1] C. Keller, "Virtual learning environments: Three implementation perspectives," Learning, Media and Technology, vol. 30, pp. 299-311, 2005.

[2] H.-K. Wu, S. W.-Y. Lee, H.-Y. Chang, and J.-C. Liang, "Current status, opportunities and challenges of augmented reality in education," Computers \& Education, vol. 62, pp. 41-49, 2013.

[3] L. Li, Y. Zheng, H. Ogata, and Y. Yano, "A framework of ubiquitous learning environment," in 4th International Conference on Computer and Information Technology (CIT 2004), Wuhan, China, 2004, pp. 345-350.

[4] B. Cope and M. Kalantzis, "Ubiquitous Learning: An Agenda for Educational Transformation," in Ubiquitous Learning, B. Cope and M. Kalantzis, Eds., ed: University of Illinois Press, 2010, pp. 3-14.

[5] M. Milrad, et al., "Seamless learning: an international perspective on next-generation technology-enhanced learning," in Handbook of Mobile Learning, Z. L. Berge and L. Y. Muilenburg, Eds., ed Abingdon: Routledge, 2013, pp. 95-108.

[6] H. Ogata, et al., "SCROLL: Supporting to share and reuse ubiquitous learning logs in the context of language learning," Research and Practice in Technology Enhanced Learning, vol. 6, pp. 69-82, 2011.

[7] J. A. Muñoz-Cristóbal, et al., "Deploying learning designs across physical and web spaces: Making pervasive learning affordable for teachers," Pervasive and Mobile Computing, vol. 14, pp. 31-46, 2014.

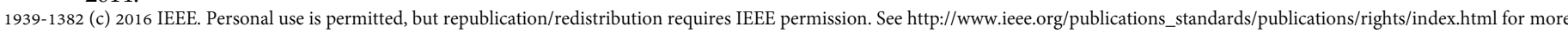

[8] E. Klopfer, et al., "Augmented reality games: place-based digital learning," in $9^{\text {th }}$ International Computer-Supported Collaborative Learning Conference, Hong Kong, China, 2011, pp. 1023-1028.

[9] P. Santos, M. Pérez-Sanagustín, D. Hernández-Leo, and J. Blat, "QuesTInSitu: From tests to routes for assessment in situ activities," Computers \& Education, vol. 57, pp. 2517-2534, 2011.

[10] L.-H. Wong and C.-K. Looi, "What Seams Do We Remove in Mobile-assisted Seamless Learning? A Critical Review of the Literature," Computers $\mathcal{E}$ Education, vol. 57, pp. 2364-2381, 2011.

[11] A. Weinberger, I. Kollar, Y. Dimitriadis, K. Mäkitalo-Siegl, and F. Fischer, "Computer-Supported Collaboration Scripts," in Technology-Enhanced Learning, N. Balacheff, et al., Eds., ed Dordrecht: Springer Netherlands, 2009, pp. 155-173.

[12] P. Dillenbourg, "Over-scripting CSCL: The risks of blending collaborative learning with instructional design," in Three worlds of CSCL. Can we support CSCL?, P. A. Kirschner, Ed., ed: Heerlen, Open Universiteit Nederland, 2002, pp. 61-91.

[13] P. Dillenbourg and P. Tchounikine, "Flexibility in macro-scripts for computer-supported collaborative learning," Journal of Computer Assisted Learning, vol. 23, pp. 1-13, 2007.

[14] M. Sharples, J. Taylor, and G. Vavoula, "A theory of learning for the mobile age," in The Sage Handbook of E-learning Research, R. Andrews and C. Haythornthwaite, Eds., ed London, UK: Sage, 2007, pp. 221-247.

[15] L. Uden, "Activity Theory for Designing Mobile Learning," International Journal of Mobile Learning and Organisation, vol. 1, pp. 81-102, 2007.

[16] Y. Miao, K. Hoeksema, H. U. Hoppe, and A. Harrer, "CSCL Scripts: Modelling Features and Potential Use," in International Conference on Computer Supported Collaborative Learning (CSCL 2005), Taipei, Taiwan, 2005, pp. 423-432.

[17] T. De Jong, et al., "Learning by creating and exchanging objects: The SCY experience," British Journal of Educational Technology, vol. 41, pp. 909-921, 2010.

[18] N. Avouris and N. Yiannoutsou, "A Review of Mobile Locationbased Games for Learning across Physical and Virtual Spaces," Journal of Universal Computer Science, vol. 18, pp. 2120-2142, 2012.

[19] M. E. C. Santos, et al., "Augmented Reality Learning Experiences: Survey of Prototype Design and Evaluation," IEEE Transactions on Learning Technologies, vol. 7, pp. 38-56, Jan 2014.

[20] P. Mulholland, et al., "nQuire: Technological Support for Personal Inquiry Learning," IEEE Transactions on Learning Technologies, vol. 5, pp. 157-169, 2012.

[21] B. Vogel, D. Spikol, A. Kurti, and M. Milrad, "Integrating Mobile, Web and Sensory Technologies to Support InquiryBased Science Learning," in 6th IEEE International Conference on Wireless, Mobile and Ubiquitous Technologies in Education (WMUTE 2010), 2010, pp. 65-72.

[22] M. Billinghurst and A. Duenser, "Augmented Reality in the classroom," Computer, vol. 45, pp. 56-63, 2012.

[23] M. Pérez-Sanagustín, A. Martínez, and C. Delgado Kloos, "EtiquetAR: a Tool for Designing Tag-based Mobile Augmented Reality Experiences," Bulletin of the IEEE Technical Committee on Learning Technology, vol. 14, pp. 27-30, 2012.

[24] S. Cuendet, Q. Bonnard, S. Do-Lenh, and P. Dillenbourg, "Designing augmented reality for the classroom," Computers $\mathcal{E}$ Education, vol. 68, pp. 557-569, 2013.

[25] L. de-la-Fuente-Valentín, D. Leony, A. Pardo, and C. Delgado Kloos, "Mashups in Learning Design: pushing the flexibility envelope," in 1st Workshop MUPPLE'08, Maastricht, The Netherlands, 2008.

[26] IMS Global Learning Consortium. (2003, November 10, 2013). IMS Learning Design information model. Available: 
http://www.imsglobal.org/learningdesign/ldv1p0/imsld infov1 p0.html

[27] D. Laurillard, et al., "A constructionist learning environment for teachers to model learning designs," Journal of Computer Assisted Learning, vol. 29, pp. 15-30, 2013.

[28] C. Martel, L. Vignollet, C. Ferraris, J.-P. David, and A. Lejeune, "Modeling Collaborative Learning Activities on e-Learning Platforms," in Sixth International Conference on Advanced Learning Technologies (ICALT), Kerkrade, The Netherlands, 2006, pp. 707 -709 .

[29] L. P. Prieto, J. A. Muñoz-Cristóbal, Y. Dimitriadis, and J. I. Asensio-Pérez, "Flexible CSCL scripting using paper, generic Augmented Reality browsers and GLUEPS-AR," in Workshop on Human-Computer Interaction and the Learning Sciences, 10th International Conference on Computer Supported Collaborative Learning (CSCL 2013), University of Wisconsin - Madison, USA, 2013.

[30] E. Bogdanov, "Widgets and Spaces: Personal \& Contextual Portability and Plasticity with OpenSocial," Ph.D. Thesis, École polytechnique fédérale de Lausanne, 2013.

[31] B. Clark and A. Booth. (2006, April 2015). SOCKET and the WAFFLE Bus for Beginners. Available: http://www.elearning.ac.uk/features/socket.html

[32] J. Dalziel, "Implementing learning design : the Learning Activity Management System (LAMS)," in 20th annual conference of the Australasian Society for Computers in Learning in Tertiary Education (ASCILITE), Adelaide, Australia, 2003.

[33] M. Dougiamas and P. Taylor, "Moodle: Using Learning Communities to Create an Open Source Course Management System," in World Conference on Educational Multimedia, Hypermedia and Telecommunications (EDMEDIA), Honolulu, Hawaii, USA, 2003, pp. 171-178.

[34] M. C. Linn, D. Clark, and J. D. Slotta, "WISE design for knowledge integration," Science Education, vol. 87, pp. 517-538, 2003.

[35] B. Simon, et al., "Applying the Widget Paradigm to Learning Design: Towards a New Level of User Adoption," in 8th European Conference on Technology Enhanced Learning (EC-TEL 2013), Paphos, Cyprus, 2013, pp. 520-525.

[36] B. Zhang, et al., "Deconstructing and reconstructing: Transforming primary science learning via a mobilized curriculum," Computers \& Education, vol. 55, pp. 1504-1523, 2010.

[37] O. Casquero, J. Portillo, R. Ovelar, M. Benito, and J. Romo, "iPLE Network: an integrated eLearning 2.0 architecture from a university's perspective," Interactive Learning Environments, vol. 18, pp. 293-308, 2010.

[38] M. Á. Conde, F. García-Peñalvo, M. Alier, E. Mayol, and C. Fernández-Llamas, "Implementation and design of a servicebased framework to integrate personal and institutional learning environments," Science of Computer Programming, vol. 88, pp. 41-53, 2014

[39] D. Griffiths, M. Johnson, K. Popat, P. Sharples, and S. Wilson, "The Wookie Widget Server: a Case Study of Piecemeal Integration of Tools and Services," Journal of Universal Computer Science, vol. 18, pp. 1432-1453, jun 2012.

[40] Y. Peter, E. D. Villasclaras-Fernández, and Y. Dimitriadis, "ThirdSpace: orchestrating collaborative activities in PLEs for formal learning," in Personal Learning Environment Conference, Berlin, Germany, 2013.

[41] E. Rahimi, J. van den Berg, and W. Veen, "Designing and Implementing PLEs in a Secondary School Using Web2.0 Tools," in PLE Conference 2012, Melbourne, Australia, 2012.
[42] R. Torres Kompen, P. Edirisingha, and R. Mobbs, "Building Web 2.0-based personal learning environments - a conceptual framework," in EDEN Research Workshop, Paris, France, 2008.

[43] S. White and H. C. Davis, "Rich and personal revisited: translating ambitions for an institutional personal learning environment into a reality," in The Second International PLE Conference, Southampton, UK, 2011.

[44] F. Wild, F. Mödritscher, and S. Sigurdarson. (2008, July). Designing for change: mash-up personal learning environments. eLearning Papers 9. Available: http://openeducationeuropa.eu/en/download/file/fid/19383

[45] A. Harrer, K. Pfahler, and A. Lingnau, "Planning for Life Educate Students to Plan: Syntactic and Semantic Support of Planning Activities with a Visual Language," in IEEE 13th International Conference on Advanced Learning Technologies (ICALT), Beijing, China, 2013, pp. 309-313.

[46] C. Cahill, A. Kuhn, S. Schmoll, A. Pompe, and C. Quintana, "Zydeco: Using Mobile and Web Technologies to Support Seamless Inquiry Between Museum and School Contexts," in $9^{\text {th }}$ International Conference on Interaction Design and Children, Barcelona, Spain, 2010.

[47] E. FitzGerald, "Situ8: browsing and capturing geolocated usercreated content," in CALRG Annual Conference 2013, The Open University, Milton Keynes, UK, 2013.

[48] A. Giemza, L. Bollen, P. Seydel, A. Overhagen, and H. U. Hoppe, "LEMONADE: A Flexible Authoring Tool for Integrated Mobile Learning Scenarios," in 6th IEEE International Conference on Wireless, Mobile and Ubiquitous Technologies in Education (WMUTE), Kaohsiung, Taiwan, 2010, pp. 73-80.

[49] F. A. Hansen and N. O. Bouvin, "Mobile Learning in Context? Context-aware Hypermedia in the Wild," International Journal of Interactive Mobile Technologies, vol. 3, pp. 6-21, 2009.

[50] A. Mikroyannidis, et al., "weSPOT: A Personal and Social Approach to Inquiry-Based Learning," Journal of Universal Computer Science, vol. 19, pp. 2093-2111, 2013.

[51] S. Seol, A. Sharp, and P. Kim, "Stanford Mobile Inquiry-based Learning Environment (SMILE): Using Mobile Phones to Promote Student Inquires in the Elementary Classroom," in The 2011 World Congress in Computer Science, Computer Engineering, and Applied Computing (WORLDCOMP 2011), Las Vegas, Nevada, USA, 2011.

[52] G. Vavoula, M. Sharples, P. Rudman, J. Meek, and P. Lonsdale, "Myartspace: Design and evaluation of support for learning with multimedia phones between classrooms and museums," Computers \& Education, vol. 53, pp. 286-299, 2009.

[53] L. Simeone and S. Iaconesi, "Anthropological Conversations: Augmented Reality Enhanced Artifacts to Foster Education in Cultural Anthropology," in 11th International Conference on Advanced Learning Technologies (ICALT 2011), Athens, GA, USA, 2011, pp. 126-128.

[54] E. Klopfer, J. Perry, K. Squire, M.-F. Jan, and C. Steinkuehler, "Mystery at the Museum: A Collaborative Game for Museum Education," in International Conference on Computer Supported Collaborative Learning (CSCL 2005), Taipei, Taiwan, 2005, pp. 316-320.

[55] E. Klopfer and J. Sheldon, "Augmenting your own reality: Student authoring of science-based augmented reality games," New Directions for Youth Development, vol. 2010, pp. 85-94, 2010.

[56] P. Santos, M. Pérez-Sanagustín, D. Hernández-Leo, and J. Blat., "Space-aware Design Factors for Located Learning Activities Supported with Smart Phones," in IEEE 10th International Symposium on Parallel and Distributed Processing with Applications (ISPA), Madrid, Spain, 2012. 
[57] M. Billinghurst and H. Kato, "Collaborative Mixed Reality," in International Symposium on Mixed Reality (ISMR '99). Mixed Reality--Merging Real and Virtual Worlds, Yokohama, Japan, 1999, pp. 261-284.

[58] E. Ghiglione and J. Dalziel, "Design Principles for LAMS Version 2 and the LAMS "ToolsContract"," in TENCompetence Open Workshop on Current research on IMS Learning Design and Lifelong Competence Development Infrastructures, Barcelona, Spain, 2007.

[59] C. Larman, Applying UML and Patterns: An Introduction to Object-Oriented Analysis and Design and the Unified Process, 2nd ed. Upper Saddle River, NJ, USA: Prentice Hall PTR, 2001.

[60] B. Butchart. (2011, October 2016). Augmented Reality for Smartphones [TechWatch Report]. Available: http://opus.bath.ac.uk/34847/1/AR_Smartphone_final.pdf

[61] C. Alario-Hoyos, et al., "GLUE!: An architecture for the integration of external tools in Virtual Learning Environments," Computers \& Education, vol. 60, pp. 122-137, 2013.

[62] C. Alario-Hoyos and S. Wilson, "Comparison of the main alternatives to the integration of external tools in different platforms," in International Conference of Education, Research and Innovation (ICERI 2010), Madrid, Spain, 2010, pp. 3466-3476.

[63] I. M. Jorrín-Abellán and R. E. Stake, "Does Ubiquitous Learning Call for Ubiquitous Forms of Formal Evaluation? An Evaluand Oriented Responsive Evaluation Model," Ubiquitous Learning: An International Journal, vol. 1, pp. 71-82, 2009.

[64] R. E. Stake, Standards-based and responsive evaluation. Thousand Oaks, CA, USA: SAGE Publications Inc., 2004.

[65] W. J. Orlikowski and J. J. Baroudi, "Studying information technology in organizations: Research approaches and assumptions," Information Systems Research, vol. 2, pp. 1-28, 1991.

[66] L. Cohen, L. Manion, and K. Morrison, Research methods in education. Abingdon, UK: Routledge, 2007.

[67] M. B. Miles and A. M. Huberman, Qualitative data analysis. An expanded sourcebook. Thousand Oaks, California, USA: SAGE Publications Inc., 1994.

[68] E. R. van Teijlingen and V. Hundley, "The importance of pilot studies," Nursing Standard, vol. 16, pp. 33-36, 2002.

[69] B. Kitchenham, S. Linkman, and D. Law, "DESMET: A methodology for evaluating software engineering methods and tools," Computing Control Engineering Journal, vol. 8, pp. 120-126, 1997.

[70] E. G. Guba, "Criteria for assessing the trustworthiness of naturalistic inquiries," Educational Communication and Technology Journal, vol. 29, pp. 75-91, 1981.

[71] D. Spikol and J. Eliasson, "Lessons from Designing Geometry Learning Activities that Combine Mobile and 3D Tools," in Proceedings of the 6th IEEE International Conference on Wireless, Mobile and Ubiquitous Technologies in Education (WMUTE), Kaohsiung, Taiwan, 2010, pp. 137-141.

[72] E. D. Villasclaras-Fernández, D. Hernández-Leo, J. I. AsensioPérez, and Y. Dimitriadis, "Web Collage: An implementation of support for assessment design in CSCL macro-scripts," Computers \& Education, vol. 67, pp. 79-97, 2013.

[73] M. Strembeck and G. Neumann, "An Integrated Approach to Engineer and Enforce Context Constraints in RBAC Environments," ACM Transactions on Information and System Security, vol. 7, pp. 392-427, 2004.

[74] F. Neven and E. Duval, "Reusable Learning Objects: A Survey of LOM-based Repositories," in Proceedings of the Tenth ACM International Conference on Multimedia, Juan les Pins, France, 2002, pp. 291-294.

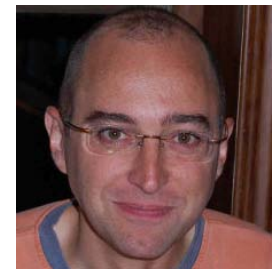

Juan A. Muñoz-Cristóbal received the PhD degree in information and telecommunications technologies from the University of Valladolid, Spain, in 2015. He is currently postdoctoral researcher at the University of Valladolid. His research interests include the orchestration of ubiquitous learning environments and the application of augmented reality and virtual worlds in education.

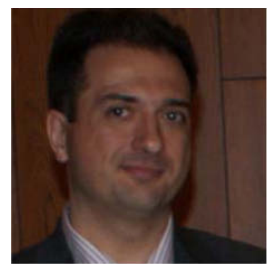

Juan I. Asensio-Pérez received the Ph.D. degree in telecommunications engineering from the University of Valladolid, Spain, in 2000 . He is currently an associate professor of telematics engineering at the University of Valladolid. His research interests within the field of Technology-Enhanced Learning include: learning design, ComputerSupported Collaborative Learning ( $\mathrm{CSCL}$ ) orchestration, and the application of Augmented Reality technologies for the support of CSCL situations across multiple virtual and physical spaces.

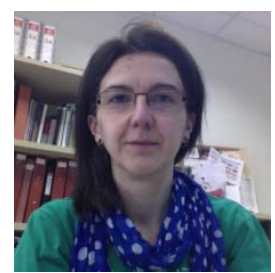

Alejandra Martínez-Monés received the PhD degree from the University of Valladolid, Spain, in 2003. She is an associate professor of Computer Science at the University of Valladolid. Her research interests in the field of Technology-Enhanced Learning relate to how to use computers to support teachers and students in the orchestration of innovative teaching and learning strategies, espe-

cially CSCL.

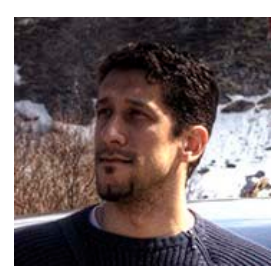

Luis P. Prieto received his Ph.D. in Information and Communication Technologies from the University of Valladolid, Spain, in 2012. He is currently a Senior Research Fellow at the School of Educational Sciences in Tallinn University (Estonia). He is also member of the Center of Excellence in Educational Innovation (HUT) at Tallinn University. His research interests include learning analytics and learning design, especially multimodal learning and teaching analytics, as well as their application for teacher professional development.

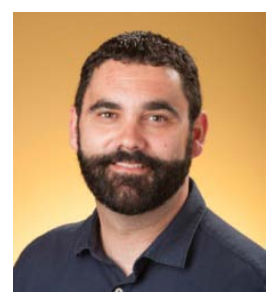

Iván M. Jorrín-Abellán received his $\mathrm{PhD}$ from the University of Valladolid, Spain, in 2006. He is associate professor of Qualitative Research methods at Kennesaw State University (USA), and former Director of the Center for Transdisciplinary Research in Education (CETIE-UVa) at the University of Valladolid (Spain). His Current research is devoted to the study of the educational implications of Computer-Supported Collaborative Learning scenarios, with special attention to new ways of evaluating these particular settings.

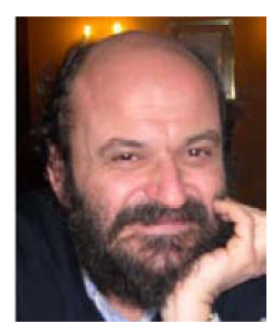

Yannis A. Dimitriadis received the $\mathrm{PhD}$ degree from the University of Valladolid, Spain, in 1992. He is currently a full professor of telematics engineering at the University of Valladolid, coordinator of the multidisciplinary research group GSIC/EMIC and Dean of the Doctoral School at the University of Valladolid. His research interests include technological support to the orchestration of computer-supported collaborative learning 